\title{
Improvement Direct Power Control on PWM using Modified Deadbeat Controller
}

\author{
Mahdi Zarif $^{1 *}$, Afsaneh Morvari ${ }^{2}$ and Masoud Goharimanesh ${ }^{3}$ \\ ${ }^{1,2.3}$ Department of Electrical Engineering, Mashhad branch, Islamic Azad \\ University, Mashhad, Iran \\ m.zarif@mshdiau.ac.ir
}

\begin{abstract}
Direct power control is a new control method of three-phase PWM converters. In this way, the internal current loop control is eliminated and the switching converter is determined, at any moment, an appropriate manner and based on the instantaneous value of the angular location vector error active and reactive power and voltage AC source. The greatest advantage of this method is to remove flow and voltage modulator control. However, variable switching frequency and the need for sampling frequency and the large inductance value is a disadvantage. In this paper, a new method for direct control of power converters based on deadbeat controller is recommended. The controller parameters are improving by Taguchi method which is a powerful technique in designing of experiments. The result show that the controller can track the desired value in different types.
\end{abstract}

Keywords: Direct power control, deadbeat controller, inductance, Taguchi method

\section{Introduction}

Recently, the sources of renewable energy such as solar and wind energy have become among most eye-catching foundations because of their economic considerations as well as environmental hazards and limitations for societies and governments. However, these sources cannot produce consistent electrical energy faced with characteristics of current power grid. According to this problem, an electronic converter is essential to transfer generated electricity from these environmental sources to a power grid [1-3]. Pulse-width modulated (PWM) voltage source converters (VSCs) are the most generally used solution to behave as an economic converter [1,2]. Providing sinusoidal currents and converting correctly is a challenge. To overcome this phenomenon, many control theories have been considered. Voltage oriented control [2], proportional-resonant control[4] and direct power control [5], are already presented in the literature. The main cause of considering these controllers are simplification and using in different applications. Among these deadbeat controllers are often considers as classical feedback controller where the control efforts are determined using a lookup- in a plant system [6-8]. Optimizing designed controller was one of the important challenge in power systems [9-11]. Using evolutionary algorithms like genetic algorithm[12] has many advantages for seeking the global point of performance in a plant [13]. Nevertheless, the lack of a precise model and using practical advices may decrease of these evolutionary algorithms. Among these, designing experiments for a power system may cause many cost and hazards. Taguchi method is a powerful DOE method which decrease the number of experiments [14-16]. This procedure can find the most effective parameter and show how the effective levels in each parameter can optimize the target of the system. In this paper after modeling a PWM system using mathematical and physical models, a deadbeat controller will be designed. Optimization of this controller for decreasing the fluctuations and meeting the target is considered using Taguchi method. The

Received (August 9, 2017), Review Result (October 18, 2017), Accepted (January 20, 2018) 
result show how this experimental optimization method can achieve the modified parameter in a power control system.

\section{Modeling}

A schematic model of three phase PWM connected grid is shown in Figure 1. This simplified model illustrates a power grid, filtration section, IGBT switches and DC port capacitor.

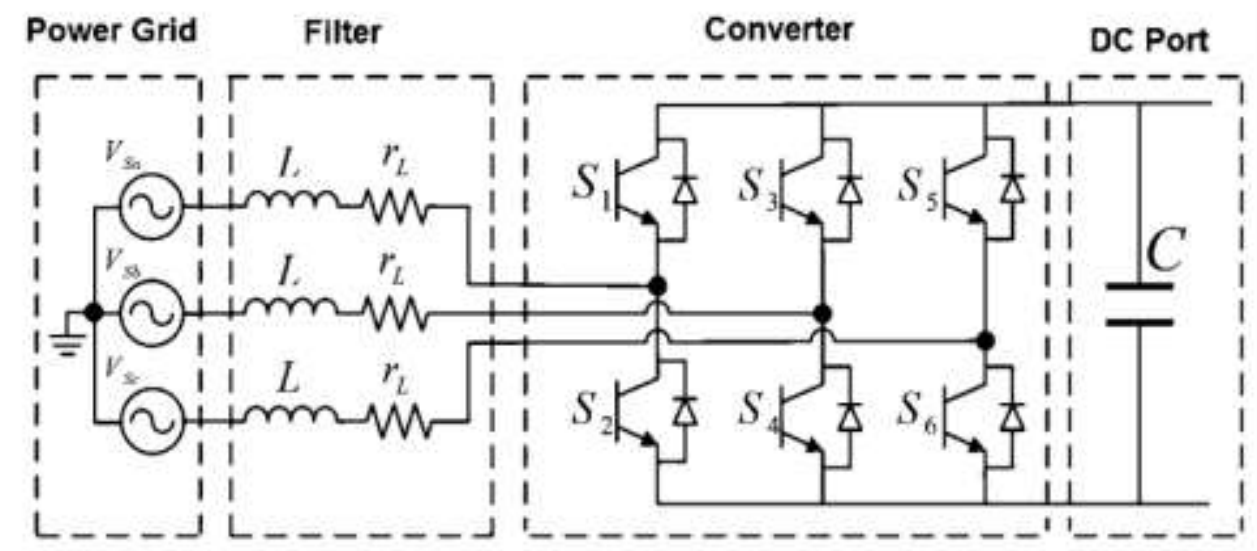

\section{Figure 1. Three Phase PWM-Vsc Connected Grid}

A mathematical model for this schematic model can be shown as (1) in stationary reference source.

$$
v_{s \alpha \beta}=r_{L} i_{\alpha \beta}+L \frac{d\left(i_{\alpha \beta}\right)}{d t}+v_{\alpha \beta}
$$

Where, $v_{\alpha \beta}, v_{S \alpha \beta}$, and $i_{\alpha \beta}$ are voltage of converter, voltage of grid and grid currents in the $\alpha \beta$ reference source, respectively. Moreover, $L$ and $r_{L}$ are inductance and equivalent resistance of the proposed filter, respectively. Considering a stable and sinusoidal three-phase system, the grid voltage modules can be introduced as (2) in $\alpha \beta$ reference frame.

$$
\left\{\begin{array}{l}
v_{s \alpha}=V_{m} \sin (\omega t) \\
v_{s \beta}=V_{m} \cos (\omega t)
\end{array}\right.
$$

By differentiating (2) respect to time we have:

$$
\left\{\begin{array}{l}
\dot{v}_{s \alpha}=\omega V_{m} \cos (\omega t) \\
v_{s \beta}=-\omega V_{m} \sin (\omega t)
\end{array}\right.
$$

This system can be expressed as a state space which is introduced as (4)/

$$
\dot{x}=A x(t)+B u(t)
$$


Where

$$
\begin{aligned}
& x=\left[\begin{array}{ll}
i_{\alpha \beta} & v_{s \alpha \beta}
\end{array}\right], u=v_{\alpha \beta}, \\
& A=\left[\begin{array}{cc}
\frac{-r_{L}}{L} I & \frac{1}{L} J \\
o & \omega J
\end{array}\right], \quad B=\left[\begin{array}{c}
\frac{1}{L} I \\
o
\end{array}\right], I=\left[\begin{array}{ll}
1 & 0 \\
0 & 1
\end{array}\right], \quad O=\left[\begin{array}{ll}
0 & 0 \\
0 & 0
\end{array}\right], J=\left[\begin{array}{cc}
0 & -1 \\
1 & 0
\end{array}\right]
\end{aligned}
$$

By Discretizing (4) with a sampling time, we have:

$$
\begin{array}{r}
x(k+1)=A_{d} x(k)+B_{d} u(k) \\
A_{d}=L^{-1}\left[(s I-A)^{-1}\right] \approx I+A T_{s}
\end{array}
$$

Where $\mathrm{s}$ is operator of Laplace and $\mathrm{L}^{-1}[\mathrm{~s}]$ is the inverse Laplace transform. The simulation of this system with facing no controller is shown in Figure 2. This openloop response shows a controller is essential to overcome the output errors.

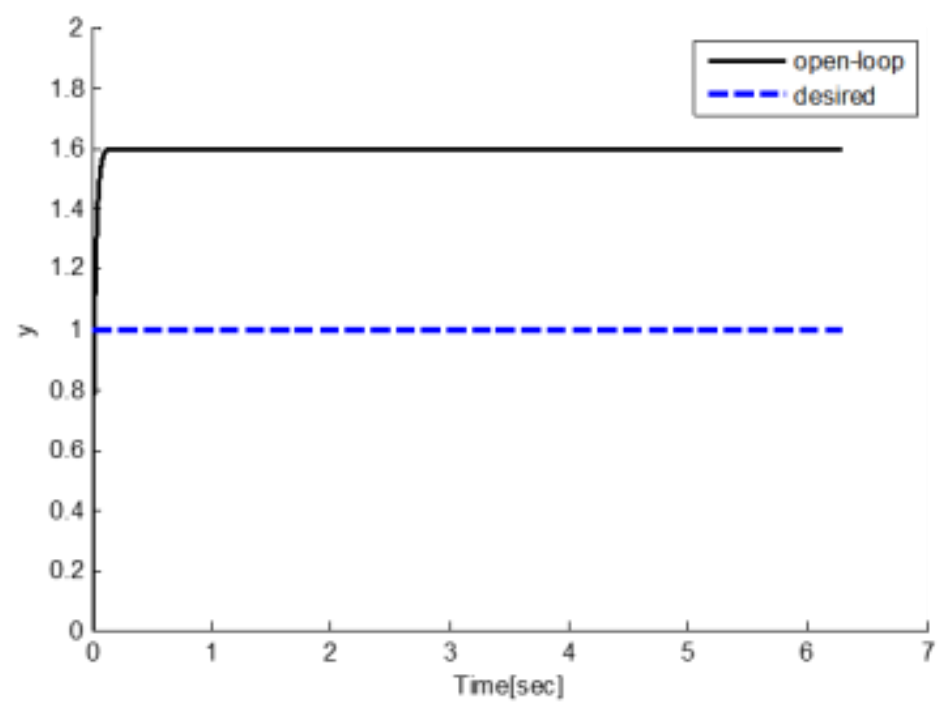

Figure 2. Open-loop Response

\section{Design of Controller}

One of useful control method is deadbeat controller which calculates the vector of voltage desire to remain the active and reactive power at zero. This method uses a discrete mathematical model of the plant. $[8,17]$. The problem is determining input value signal for a discrete system to achieve the smallest number of time steps in steady state. In an Nth-order linear system we can show that the minimum amount of steps goes to N. The deadbeat response has the following characteristics Figure 4. 


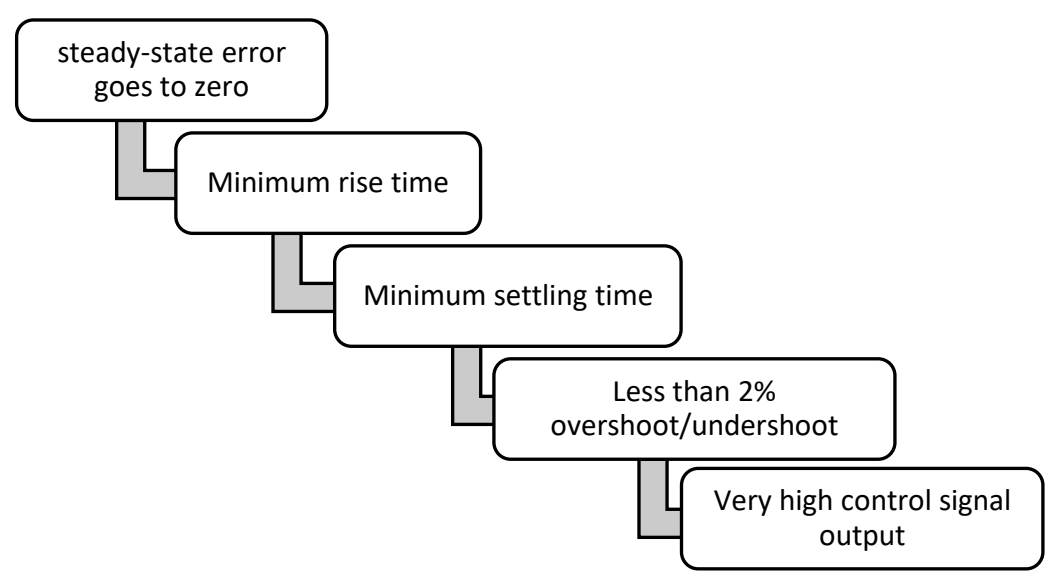

Figure 3. Deadbeat Controller Designing Procedure

A scheme of model and proposed controller is shown in Figure 4. The transfer function of plant and controller is shown by $\mathrm{G}_{\mathrm{p}}(\mathrm{z})$ and $\mathrm{D}_{\mathrm{c}}(\mathrm{z})$, respectively in (7) and (8).

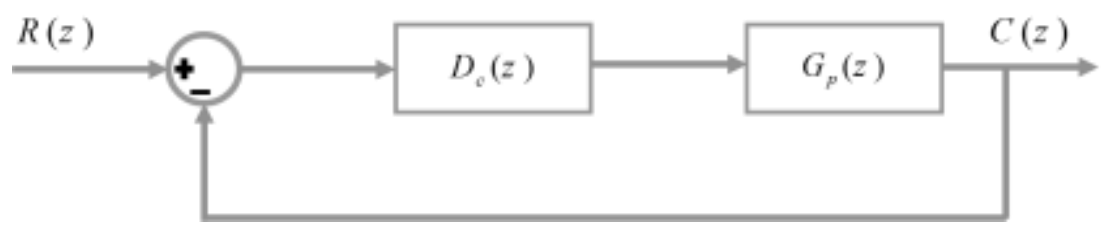

Figure 4. A Schematic of the Main System Controller Function

$$
\begin{aligned}
& M(z)=\frac{C(z)}{R(z)}=\frac{D_{c}(z) G_{p}(z)}{1+D_{c}(z) G_{p}(z)} \\
& D_{c}(z)=\frac{1}{G_{p}(z)}=\frac{1}{1-M(z)}
\end{aligned}
$$

Signal error can calculated as shown in (9).

$$
E(z)=R(z)-C(z)=\frac{R(z)}{1+D_{c}(z) G_{p}(z)}
$$

Supposing a fraction (10).

$$
R(z)=\frac{A(z)}{\left(1-z^{-1}\right)^{N}}
$$

Where $\mathrm{A}(\mathrm{z})$ is $(\mathrm{z}-1)$ order polynomial and $\mathrm{N}$ is appositive integer. Zero steady state error can be expressed as (11) 


$$
\begin{aligned}
\lim _{k \rightarrow \infty} e(k T) & =\lim _{z \rightarrow 1}\left(1-z^{-1}\right) E(z) \\
& =\lim _{z \rightarrow 1} \frac{\left(1-z^{-1}\right) A(z)(1-M(z))}{\left(1-z^{-1}\right)^{N}}=0
\end{aligned}
$$

Where

$$
M(z)=1-\left(1-z^{-1}\right)^{N} F(z)=\frac{Q(z)}{z^{p}}, p>N
$$

The controller rule can be obtained as (13)

$$
\begin{aligned}
& G_{p}(z)=g_{n} z^{-n}+g_{n+1} z^{-n-1}+\ldots \\
& M(z)=m_{k} z^{-k}+m_{k+1} z^{-k-1}+\ldots
\end{aligned}
$$

Which can be simplified as (14).

$$
D_{c}(z)=d_{k-n} z^{-(k-n)}+d_{k-n+1} z^{-(k-n+1)}+\ldots
$$

\section{Optimizing Controller}

The controller transfer function was designed in the previous section can be introduced in (15)

$$
G_{c}(z)=P_{1} / G_{p}(z)+p_{2} /\left(z-p_{3}\right)
$$

Where $\mathrm{P}_{1}, \mathrm{P}_{2}$ and $\mathrm{P}_{3}$ are three parameters should be achieved by Taguchi method. The $G(p)$ is a transfer function of system

Taguchi method is a powerful tool for characterization, design and performance optimization [14-16, 18-20]. The Taguchi experimental design method offers a wide range of applications, with advantages such as simple concept, ease of use, as well as variation reduction [21].

This technique has seven steps [21].

1- Purpose a function that needs to be improved.

2- Purpose of controllable factors and their levels.

3- Variety of an appropriate orthogonal array.

4- Performing the experiments and measuring outputs.

5- Calculation of $\mathrm{S} / \mathrm{N}$ ratio.

6- Choosing the parameters corresponding to optimal conditions, studying the data and prediction of output in optimum case.

7- Showing the confirmation test.

In Taguchi method, a loss function is used to take the cost of deviation from target into consideration. The loss function is further transformed into $\mathrm{S} / \mathrm{N}$ ratio. It delivers a measure, to comprehend the impact of noise factors on the performance of the 
system. In this study, the smaller error of observed and tracked value is a better performance (16).

$$
S N R_{S B}=-10 \log \left(\frac{1}{n} \sum_{i=1}^{n} y_{i}^{2}\right)
$$

In this study, three control parameters are investigated by Table 1.

Table 1. Deadbeat Control Parameters and their Levels

\begin{tabular}{llll}
\hline Levels & P1 & P2 & P3 \\
\hline 1 & 0.7 & 0.7 & 0.7 \\
2 & 0.8 & 0.8 & 0.8 \\
3 & 0.9 & 0.9 & 0.9 \\
4 & 1 & 1 & 1 \\
5 & 1.1 & 1.1 & 1.1 \\
\hline
\end{tabular}

\section{Results and Simulation}

In this study, Matlab-Simulink is employed for simulation. Figure 5 shows the entire blocks in Simulink environment.

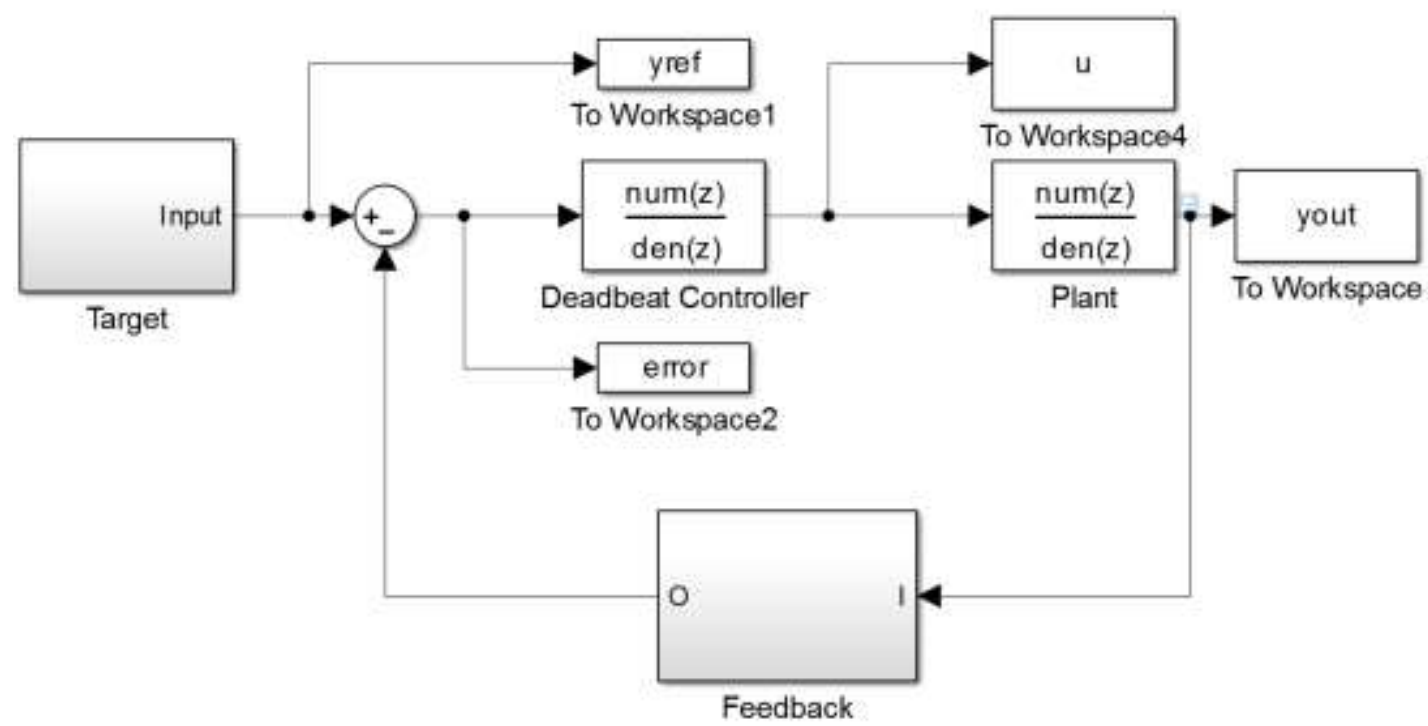

Figure 5. Simulation and Control Systems in Simulink

The result will be as follows in Figure 6. As shown, some random desired values have been examined and controller could track all of the desired values. The primary intention of using these random values is to investigate if controller could withstand changing the conditions. 

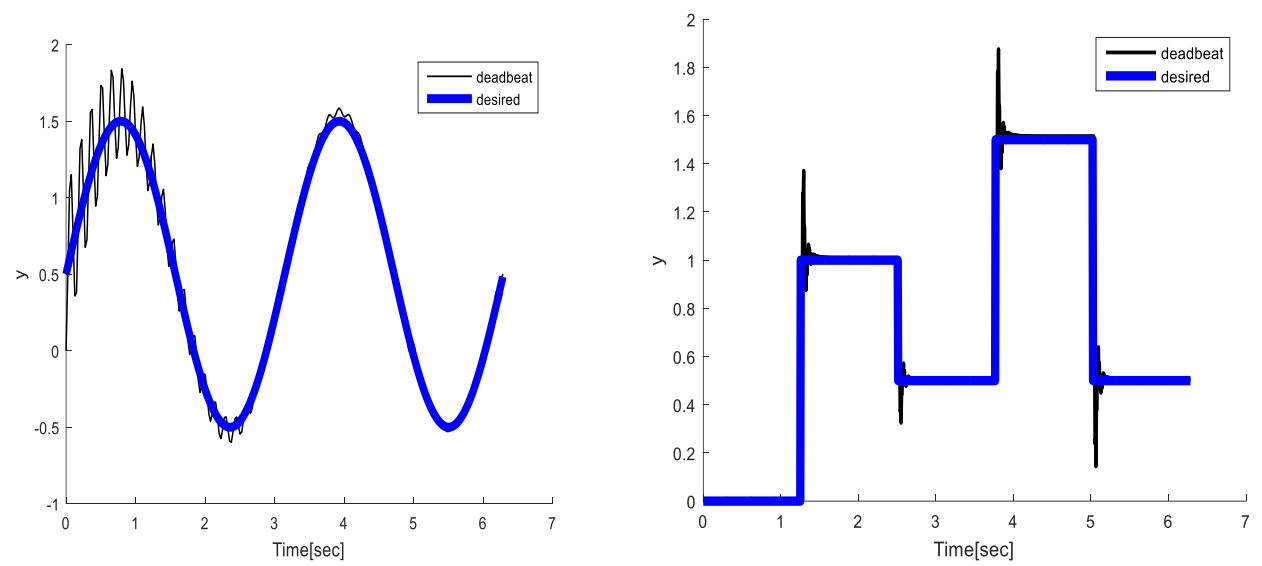

Figure 6. Result for Deadbeat Controller in Tracking the Desired Value

The fluctuations may be seen in Figure 6 can be omitted by optimizing the control parameters.

The experimental data for this problem was simulated in MATLAB and the error of desired and feedback value was recorded in each experiment. The results are shown in Table 2.

Table 2. Experimental Data with Taguchi L25

\begin{tabular}{llll}
\hline $\mathrm{p} 1$ & $\mathrm{p} 2$ & $\mathrm{p} 3$ & error \\
\hline 1 & 1 & 1 & 480.2003 \\
1 & 2 & 2 & 350.4732 \\
1 & 3 & 3 & 194.1568 \\
1 & 4 & 4 & 2.479652 \\
1 & 5 & 5 & 243.8331 \\
2 & 1 & 2 & 350.4732 \\
2 & 2 & 3 & 191.7041 \\
2 & 3 & 4 & 2.51649 \\
2 & 4 & 5 & 232.7491 \\
2 & 5 & 1 & 339.6917 \\
3 & 1 & 3 & 194.1568 \\
3 & 2 & 4 & 2.516491 \\
3 & 3 & 5 & 229.2767 \\
3 & 4 & 1 & 334.7156 \\
3 & 5 & 2 & 234.3761 \\
4 & 1 & 4 & 2.479652 \\
4 & 2 & 5 & 232.7491 \\
4 & 3 & 1 & 334.7156 \\
4 & 4 & 2 & 232.6059 \\
\hline & & &
\end{tabular}




\begin{tabular}{llll}
\hline 4 & 5 & 3 & 122.7827 \\
5 & 1 & 5 & 243.8331 \\
5 & 2 & 1 & 339.6917 \\
5 & 3 & 2 & 234.3761 \\
5 & 4 & 3 & 122.7827 \\
5 & 5 & 4 & 5.747725 \\
\hline
\end{tabular}

The immunizing error was the aim of this study. For this reason, smaller better for signal to noise ratio index is selected. Three parameters are compared in Figure 7. where $\mathrm{p}_{3}$ was the effective parameter and $\mathrm{p}_{1}$ and $\mathrm{p}_{2}$ are not as effective as variables in control designing. However, the fourth level of these parameter are the highest SNR value which address the minimum error for implementing deadbeat controller system. The effective parameter can also be checked by analysis of variance which is shown in Table 3. The most effective parameter in ANOVA table was demonstrated by the minimum of $\mathrm{p}$-value which is $\mathrm{p}_{3}$ as described before.

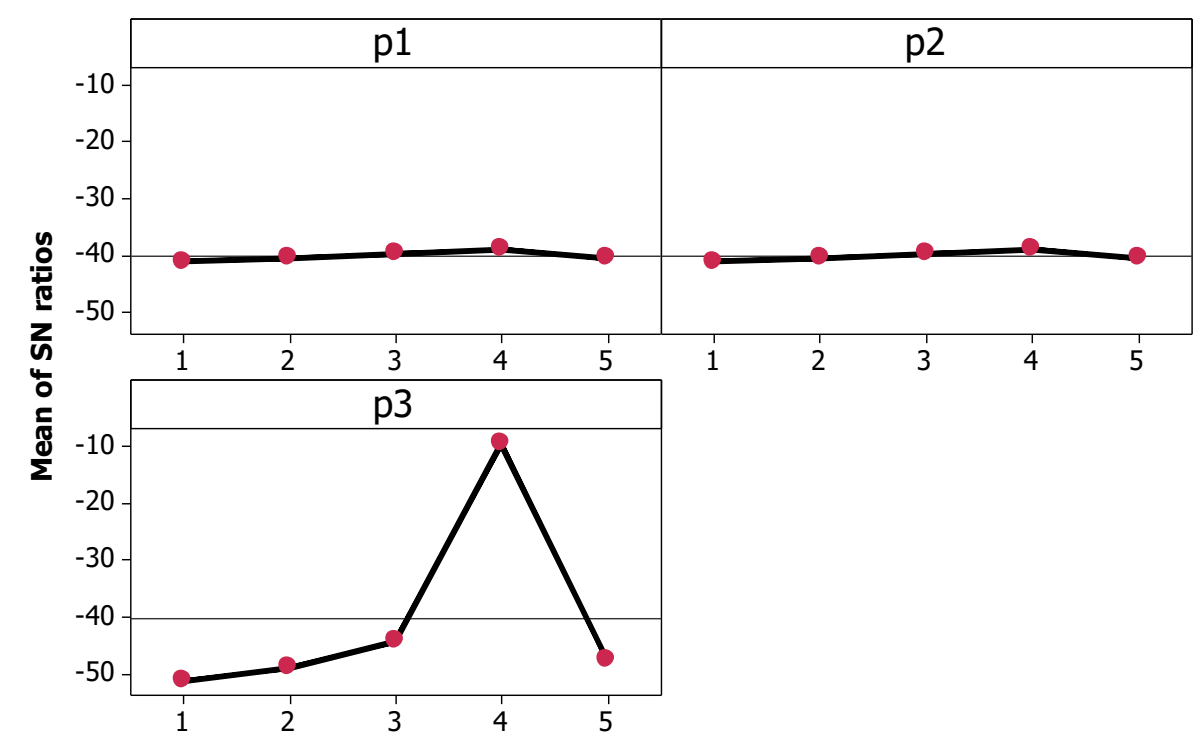

Signal-to-noise: Smaller is better

Figure 7. Signal to Noise Ratio Graph

Table 3. Analysis of Variance

\begin{tabular}{lllllll}
\hline Source & DF & SeqSS & SSAdj & MS & F & P \\
\hline p1 & 1 & 14153 & 14153 & 14153 & 1.23 & 0.279 \\
p2 & 1 & 14153 & 14153 & 14153 & 1.23 & 0.279 \\
p3 & 1 & 143617 & 143617 & 143617 & 12.53 & 0.002 \\
Error & 21 & 240690 & 240690 & 11461 & & \\
Total & 24 & 412614 & & & & \\
\hline
\end{tabular}


The result of improved controller for two step and sinusoidal input are shown in Figure 6. . the figures show how the improved controller can decrease the fluctuation and increase the performance of power system.
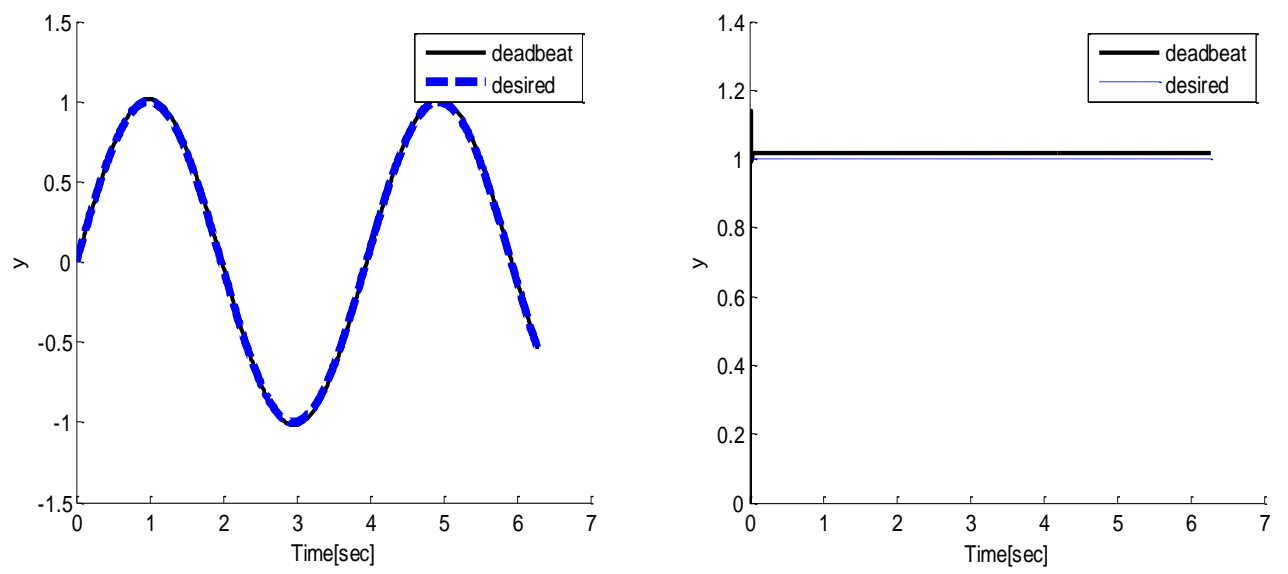

Figure 6. Result of Deadbeat Controller Improved by Taguchi Method

\section{Conclusion}

In this paper, a deadbeat controller for direct control of power converters based on PWM deadbeat controller is employed. To face in a real environment and find a procedure for designing effective controller, three parameter of deadbeat compensators are considered and investigated by Taguchi method which is powerful method in design of experiment procedure. The designed controller shows a reliable result for tracking desired values.

\section{References}

[1] Q. Huang, K. Qin and W. Wang, "Development of a grid computing platform for electric power system applications", Power Engineering Society General Meeting, IEEE, (2006).

[2] R. Kadri, J.-P. Gaubert and G. Champenois, "An improved maximum power point tracking for photovoltaic grid-connected inverter based on voltage-oriented control", IEEE Transactions on Industrial Electronics, vol. 58, (2011), pp. 66-75.

[3] V. Raghunathan, A. Kansal, J. Hsu, J. Friedman and M. Srivastava, "Design considerations for solar energy harvesting wireless embedded systems", Proceedings of the 4th international symposium on Information processing in sensor networks, (2005), p. 64.

[4] C. Xia, F. Zhou, Z. Wang and X. He, "Equivalent switch circuit model and proportional resonant control for triple line-voltage cascaded voltage-source converter," IEEE Transactions on Power Electronics, vol. 28, pp. 2389-2401.

[5] T. Noguchi, H. Tomiki, S. Kondo and I. Takahashi, "Direct power control of PWM converter without power-source voltage sensors", IEEE Transactions on Industry Applications, vol. 34, (1998), pp. 473-479.

[6] A. Kawamura, R. Chuarayapratip and T. Haneyoshi, "Deadbeat control of PWM inverter with modified pulse patterns for uninterruptible power supply", IEEE Transactions on Industrial Electronics, vol. 35, (1988), pp. 295-300.

[7] S.-J. Park, F.-S. Kang, M. H. Lee and C.-U. Kim, "A new single-phase five-level PWM inverter employing a deadbeat control scheme", IEEE Transactions on power electronics, vol. 18, (2003), pp. 831-843.

[8] S. Buso, T. Caldognetto and D. I. Brandao, "Dead-Beat Current Controller for Voltage-Source Converters With Improved Large-Signal Response", IEEE Transactions on Industry Applications, vol. 52, (2016), pp. 1588-1596.

[9] D. Chindamo, J. T. Economou, M. Gadola and K. Knowles, "A neurofuzzy-controlled power management strategy for a series hybrid electric vehicle", Proceedings of the Institution of Mechanical Engineers, Part D: Journal of Automobile Engineering, p. 0954407014522777, (2014).

[10] S. Hesari and M. B. N. Sistani, "Efficiency improvement by timely controlling power factor in permanent magnet synchronous motor using PSO algorithm", in Technology, Communication and Knowledge (ICTCK), 2014 International Congress, (2014), pp. 1-4. 
[11] M. Esfandiari and N. Sepehri, "Stability Analysis of QFT Controllers Designed for Hydraulic Actuators Using Takagi-Sugeno Fuzzy Modeling Approach", ASME/BATH 2013 Symposium on Fluid Power and Motion Control, (2013), pp. V001T01A031-V001T01A031.

[12] D. Kwok and F. Sheng, "Genetic algorithm and simulated annealing for optimal robot arm PID control", in Evolutionary Computation, 1994. IEEE World Congress on Computational Intelligence., Proceedings of the First IEEE Conference, (1994), pp. 707-713.

[13] M. Goharimanesh, A. Lashkaripour, S. Shariatnia and A. Akbari, "Diabetic Control Using Genetic FuzzyPI Controller", International Journal of Fuzzy Systems, vol. 16, (2014), pp. 133.

[14] G. Taguchi, "Introduction to quality engineering: designing quality into products and processes", Tokyo, The Organization, (1986).

[15] G. Taguchi, L. W. Tung and D. Clausing, "System of experimental design: engineering methods to optimize quality and minimize costs", UNIPUB/Kraus International Publications, vol. 2, (1987).

[16] G. Taguchi, E. A. Elsayed and T. C. Hsiang, "Quality engineering in production systems", McGraw-Hill College, (1989).

[17] J.-H. Kim, S.-T. Jou, D.-K. Choi and K.-B. Lee, "Direct power control of three-phase boost rectifiers by using a sliding-mode scheme", Journal of Power Electronics, vol. 13, (2013), pp. 1000-1007.

[18] K. N. Otto and E. K. Antonsson, "Extensions to the Taguchi method of product design", TransactionsAmerican society of mechanical engineers journal of mechanical design, vol. 115, (1993), pp. 5-5.

[19] G. Taguchi and V. Cariapa, "Taguchi on robust technology development", Journal of pressure vessel technology, vol. 115, (1993), pp. 336

[20] G. I. Taguchi and Y. Yokoyama, "Taguchi methods", ASI, vol. 2, (1994).

[21] M. Goharimanesh, A. Akbari and A. A. Tootoonchi, "More efficiency in fuel consumption using gearbox optimization based on Taguchi method", Journal of Industrial Engineering International, vol. 10, (2014), pp. 1-8. 